\title{
La utilización de objetos de aprendizaje en realidad aumentada en la enseñanza de la medicina
}

\author{
The use of learning objects in augmented reality in the teaching of medicine
}

\author{
Julio Barroso Osuna ${ }^{1}$, Julio Cabero Almenara ${ }^{2}$, Ana María Moreno Fernández ${ }^{3}$ \\ ${ }^{1}$ Departamento Didáctica y Organización Escolar, Universidad de Sevilla, España (jbarroso@us.es) \\ ${ }^{2}$ Departamento Didáctica y Organización Escolar, Universidad de Sevilla, España (cabero@us.es) \\ ${ }^{3}$ Departamento Citología e Histología Normal y Patológica, Universidad de Sevilla, España (anamf@us.es)
}

Recibido el 26 de mayo de 2016; revisado el 17 de junio de 2016; aceptado el 25 de junio de 2016; publicado el 2 de diciembre de 2016

\section{RESUMEN:}

La realidad aumentada (RA) se configura como una tecnología de gran potencial en la formación universitaria, ofreciendo la posibilidad de combinar la información digital con la física en tiempo real a través de diferentes dispositivos tecnológicos (tablet, smartphones, gafas,...). Nuestro estudio perseguía un doble objetivo: por una parte, conocer el grado de motivación que la utilización de objetos en formato RA despierta en los alumnos de medicina y, por otra, analizar si el género de los alumnos afecta positivamente en el grado de motivación mostrada. Para el análisis de la motivación despertada en los alumnos por la experiencia realizada con los objetos de RA elaborados se utilizó un cuestionario elaborado por Keller (2010), el "Instructional Material Motivational Survey" (IMMS). La muestra del estudio estuvo formada por alumnos de primer curso del Grado de Medicina de la Universidad de Sevilla (España), que cursaban la asignatura de "Histología Humana". Podemos destacar que la experiencia realizada llamó la atención de los alumnos, y que el material les despertó la curiosidad ayudándoles a mantener la atención y disfrutando, por lo general, con la experiencia realizada a la vez que el contenido del material presentado era relevante para sus intereses. Del estudio podemos sacar las siguientes conclusiones: el instrumento de diagnóstico se presenta como un buen predictor para explicar la motivación, atención, confianza, relevancia y satisfacción que despierta la interacción con los objetos de RA. La RA se presenta como una tecnología de gran utilidad para el aprendizaje de los alumnos de medicina, su incorporación a la enseñanza es fácil y el género de los estudiantes no determina el grado de aceptación que tienen de la RA.

PALABRAS CLAVE: REALIDAD AUMENTADA; INTEGRACIÓN CURRICULAR; DISEÑO, PRODUCCIÓN Y EVALUACIÓN DE MEDIOS Y MATERIALES; TECNOLOGÍAS EMERGENTES.

\section{ABSTRACT:}

The Augmented Reality (AR) is formed as a technology of great potential in the universitary education, offering the possibility of combining the digital information with the real time physics across different technological devices (tablet, smartphones, glasses ...). Our study was chasing an objective double, on one hand to know the degree of motivation that the utilization of objects in format AR wakes up in the medical student and for analyzing other one if the kind of the student concerns positively in the degree of showed motivation. For the analysis of the motivation woken up in the student for the experience realized with the 
objects of elaborated AR a questionnaire was in use elaborated for Keller (2010), the "Instructional Material Motivational Survey" (IMMS). The sample of the study was formed by student of the first year of the Degree of Medicine of the University of Seville (Spain), who were dealing the subject of "Human Histology". We can emphasize that the realized experience called the attention of the student, and that the material they woke the curiosity up helping them to support the attention and enjoying in general with the experience realized simultaneously that the content of the presented material was relevant for his interests. Of The study we can extract the following conclusions: The instrument of diagnosis appears as a good predictor to explain the motivation, attention, confidence, relevancy and satisfaction that wakes the interaction up with AR's objects. The AR appears as a technology of great utility for the learning of the student of medicine, his incorporation to the education is easy and the gender of the students does not determine the degree of acceptance that they have of the AR.

\section{KEYWORDS: AUGMENTED REALITY; CURRICULAR INTEGRATION; DESIGN, PRODUCTION AND EVALUATION OF MEANS AND MATERIALS; EMERGENT TECHNOLOGIES.}

\section{INTRODUCCIÓN}

La RA se está convirtiendo en una tecnología emergente con grandes posibilidades en la formación universitaria, como señala el último Informe Horizon (Johnson et al., 2016) y el Reporte EduTrend (Tecnológico de Monterrey, 2015).

Por RA se entiende la combinación de información digital e información física en tiempo real a través de diferentes dispositivos tecnológicos (tablet, smartphone, gafas,...); es decir, consiste en utilizar un conjunto de dispositivos tecnológicos que añaden información virtual a la información física, para crear una nueva realidad donde tanto la información real como la virtual desempeñan un papel significativo (Fombona, Pascual, y Madeira, 2012; Prendes, 2015; Cabero y Barroso, 2016; Cabero y García, 2016).

Cabero y García (2016) señalan sus propiedades más significativas: ser una realidad mixta, integrada en tiempo real, que posee una diversidad de capas de información digital, que es interactiva y que, mediante su utilización, enriquecemos o alteramos la información.

En la enseñanza de la medicina empezamos a contar con experiencias (Bower, Howe, McCredie, Robinson y Grover, 2014; Mott el al., 2008; Yeo et al., 2011; Wu, Wen-Yu, Chang y Liang, 2013), que nos indican que puede ser una tecnología de utilidad para su enseñanza. De todas formas, uno de sus problemas es la falta de investigación.

El estudio que presentamos se enmarca en el proyecto de I+D+i RAFODIUN (EDU2014-57446P) financiado por el Ministerio de Economía y Competividad de España, y entre sus diversos objetivos persigue producir contenidos en formato RA para su aplicación en la enseñanza universitaria $\mathrm{y}$ conocer el grado de motivación que esta tecnología despierta en los estudiantes.

\subsection{Objetos en RA producidos}

Cuatro fueron los objetos en RA que se produjeron para nuestra investigación: Coxofemoral, Shoulder, Ankle y Cervical. Fueron creados con los programas "Metaio Creator" y "Metaio SDK", y poseen las siguientes características: animaciones en 3D, parada y seguimiento del objeto, ampliación del tamaño del componente presentado para que puedan ser observados los detalles y transferencia a un vídeo ampliador de la información ubicado en YouTube (figura 1). Los objetos funcionan tanto para dispositivos Android como iOS y las app pueden descargarse http://intra.sav.us.es/proyectorafodiun/.
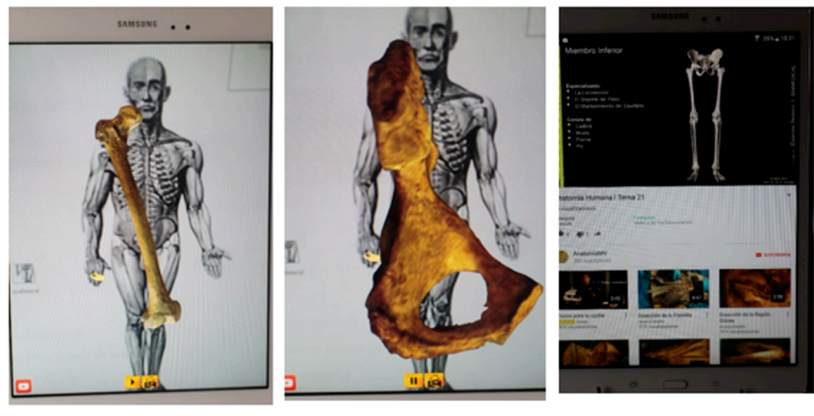

Figura 1. Objetos producidos en RA.

La presentación de los objetos a los alumnos se realizó en una sesión de dos horas, donde se realizaron las siguientes actividades:

- Explicación de en qué consistía la RA.

- Demostración de los diferentes objetos producidos y sus posibilidades.

- Presentación del lugar donde podrían bajarse las distintas guías y app de los objetos producidos. 
- Trabajo individual de los alumnos con sus dispositivos móviles con los diferentes objetos.

- Y cumplimentación de los cuestionarios.

\section{LA INVESTIGACIÓN REALIZADA}

\subsection{Objetivos}

Con este estudio piloto pretendemos evaluar las posibilidades que ofrecen los objetos de RA en la docencia universitaria.

Concretamente nuestra investigación persigue dos objetivos básicos:

- Conocer el grado de motivación que la utilización de objetos de aprendizaje en formato RA despierta en los alumnos de medicina.

- Analizar si el género de los alumnos puede afectar positiva y significativamente en el grado de motivación mostrada.

\subsection{Instrumento de recogida de información}

El instrumento que hemos utilizado para el análisis de la motivación despertada en los estudiantes por la experiencia realizada con los objetos de RA elaborados para el estudio fue el "Instructional Material Motivational Survey" (IMMS) elaborado por Keller (2010). Pretende recoger información en cuatro grandes dimensiones: atención, confianza, relevancia y satisfacción. Para Keller (2010) la categoría de atención incluye características humanas tales como el reflejo orientación, la curiosidad y la búsqueda de sensaciones; la relevancia, se refiere a aquellas cosas que la persona percibe como un instrumento para satisfacer las necesidades y la satisfacción personal, incluyendo el cumplimiento de los objetivos personales; la confianza, que como señala el propio autor es un concepto complejo que abarca varios constructos motivacionales que van desde aquellos que explican las percepciones de control personal y la esperanza para el éxito en el extremo opuesto a la impotencia; siendo el paso final en el proceso motivacional el crear satisfacción por lo que se continuará la motivación para aprender.

El instrumento está compuesto por 36 ítems, con construcción tipo Likert, con siete opciones de respuesta, desde $1=$ Extremadamente improbable/en desacuerdo a 7=Extremadamente probable/de acuerdo. En el anexo del presente artículo se presenta el instrumento utilizado. El instrumento ha sido utilizado por diferentes autores para conocer el grado de motivación que despierta en los estudiantes la interacción con las tecnologías (Bolliger, Supanakorn y Boggs, 2010; Chen, 2012; Di Serio, Blanca y Delgado, 2012).

Para la obtención del índice de fiabilidad aplicamos la alfa de Cronbach que, de acuerdo con O'Dwyer y Bernauer (2014), es el estadístico apropiado para este tipo de instrumentos, alcanzando los valores que presentamos a continuación:

- Total del instrumento: .898.

- Atención: ,704

- Confianza: ,582

- Relevancia: ,746

- Satisfacción: ,775

Todos los valores, salvo el correspondiente a la dimensión "confianza", poseen un nivel de fiabilidad que podemos considerar de acuerdo con Mateo (2004) de alta. Al mismo tiempo, se obtuvo ítemtotal por el mismo procedimiento, para saber si eliminando algún ítem aumentaría la fiabilidad del instrumento, hecho que no ocurrió y, por tanto, se mantuvieron todos los ítems del instrumento de Keller (2010). La correlación total obtenida por nosotros en el instrumento es muy similar a la alcanzada en otros trabajos (Chen, 2013; Keller, 2010).

El instrumento fue anónimo, incluía una pregunta para identificar el género del estudiante y se administró vía Internet, tras la interacción de los alumnos con los cuatro objetos en RA producidos.

\subsection{Muestra}

La muestra del estudio piloto estuvo formada por 50 alumnos (21 hombres-42\% y 29 mujeres-58\%) de primer curso del Grado de Medicina de la Universidad de Sevilla y que cursaban la asignatura de "Histología Humana". Se trata de una muestra incidental de los alumnos que quisieron participar en el estudio, de entre la totalidad de los matriculados en primer curso del Grado de Medicina en la asignatura comentada anteriormente.

\section{RESULTADOS}

Por lo que se refiere a las valoraciones medias y desviaciones típicas alcanzadas para la globalidad del instrumento y las diferentes dimensiones que lo conformaban; en la tabla 1, presentamos los citados valores.

Tabla 1. Medias y desviaciones típicas del IMMS

Dimensión Media $\quad \begin{gathered}\text { Desviación } \\ \text { típica }\end{gathered}$




\begin{tabular}{ccc}
\hline Total del instrumento & 4,39 &, 71 \\
\hline Atención (A) & 4,33 &, 71 \\
\hline Confianza (C) & 4,10 &, 77 \\
\hline Relevancia (R) & 4,64 &, 85 \\
\hline Satisfacción (S) & 4,56 & 1,06
\end{tabular}

Como podemos observar en la tabla 1 , los valores medios alcanzados tienden a situarse por encima del valor central de la escala: 3,5; lo que nos indica un cierto grado de acuerdo con la experiencia realizada en RA; destacando ligeramente las medias en las categorías de satisfacción y relevancia. Indicar también que las desviaciones típicas alcanzadas muestran cierta uniformidad en las puntuaciones.

En la tabla 2, presentamos las medias y desviaciones típicas alcanzadas en todos los ítems.

Tabla 2. Medias y desviaciones típicas de todos los ítems

\begin{tabular}{|c|c|c|}
\hline Ítem & Media & $\begin{array}{l}\text { Desviación } \\
\text { típica }\end{array}$ \\
\hline $\begin{array}{l}\text { 1 Cuando vi por primera vez la } \\
\text { lección, tuve la impresión de que } \\
\text { sería fácil para mí }(\mathrm{C})\end{array}$ & 4,82 & 1,22 \\
\hline $\begin{array}{l}2 \text { Había algo interesante en los } \\
\text { materiales con RA que me llamó } \\
\text { la atención }(\mathrm{A})\end{array}$ & 4,82 & 1,45 \\
\hline $\begin{array}{c}3 \text { Este material es más difícil de } \\
\text { entender de lo que me gustaría } \\
\text { que fuera (C) }\end{array}$ & 3,56 & 1,80 \\
\hline $\begin{array}{l}4 \text { Después de la información de } \\
\text { introducción, me sentí seguro de } \\
\text { que yo sabía lo que tenía que } \\
\text { aprender de esta lección }(\mathrm{C})\end{array}$ & 4,58 & 1,43 \\
\hline $\begin{array}{l}5 \text { Completar los ejercicios de esta } \\
\text { lección me dio una sensación de } \\
\text { satisfacción de logro }(\mathrm{S})\end{array}$ & 4,38 & 1,47 \\
\hline $\begin{array}{l}6 \text { Es claro para mí cómo el } \\
\text { contenido de este material está } \\
\text { relacionado con cosas que ya sé } \\
(\mathrm{R})\end{array}$ & 5,10 & 1,25 \\
\hline $\begin{array}{l}7 \text { La información era tanta que } \\
\text { me era difícil recordar los puntos } \\
\text { importantes }(\mathrm{C})\end{array}$ & 3,50 & 1,73 \\
\hline $\begin{array}{c}8 \text { La tecnología de la RA me } \\
\text { llama la atención }(\mathrm{A})\end{array}$ & 5,34 & 1,33 \\
\hline $\begin{array}{l}9 \text { No había imágenes, vídeos y } \\
\text { textos que me mostraron cómo } \\
\text { este material podría ser } \\
\text { importante para algunas personas } \\
(\mathrm{R})\end{array}$ & 3,84 & 1,81 \\
\hline $\begin{array}{l}10 \text { Completar esta lección con } \\
\text { éxito era importante para mí }(\mathrm{R})\end{array}$ & 4,84 & 1,48 \\
\hline $\begin{array}{l}11 \text { La calidad del material en RA } \\
\text { me ayudó a mantener la atención } \\
(\mathrm{A})\end{array}$ & 4,60 & 1,67 \\
\hline $\begin{array}{l}12 \text { El material era tan abstracto } \\
\text { que era difícil mantener mi }\end{array}$ & 3,38 & 1,54 \\
\hline
\end{tabular}

atención en él (A)

13 Mientras trabajaba en esta

4,86

1,29

lección, yo estaba seguro de que podía aprender el contenido (C)

14 He disfrutado esta lección tanto que me gustaría saber más sobre este tema $(\mathrm{S})$

15 Las imágenes, vídeos y textos

$4,20 \quad 1,63$ que he descubierto a través de la lección son poco atractivos (A)

16 El contenido de este material es relevante para mis intereses

17 La forma de organizar la $4,62 \quad 1,52$

información usando esta tecnología me ayudó a mantener la atención (A)

18 Hay explicaciones o ejemplos $\quad 4,56 \quad 1,43$ de cómo la gente usa el conocimiento de esta lección $(\mathrm{R})$

19 Era difícil descubrir la

$3,70 \quad 1,46$

$5,04 \quad 1,44$
información digital asociada con la imagen real (C)

20 La información descubierta a través de la experiencia estimuló mi curiosidad (A)

21 Me gustó mucho el estudio de $\quad 4,88 \quad 1,45$ esta lección (S)

22 La cantidad de repetición de
las actividades me aburre (A)

23 El contenido y el material

$3,92 \quad 1,46$

audiovisual en esta lección

$5,02 \quad 1,35$

transmiten la impresión de que su contenido vale la pena conocer

24 He aprendido algunas cosas de la RA que fueron sorprendentes o inesperadas $(\mathrm{A})$

25 Después de trabajar en esta lección por un tiempo, yo estaba seguro de que iba a ser capaz de pasar una prueba sobre el contenido presentado (C)

26 Esta lección no era relevante para mis necesidades, porque yo

$4,50 \quad 1,71$
4,66 1,41 ya sabía más del contenido $(\mathrm{R})$
27 Los logros alcanzados, me

ayudaron a sentirme
recompensado por mi esfuerzo

$3,66 \quad 1,62$

$4,70 \quad 1,47$
(S)

28 La variedad de material 4,78 1,20 audiovisual ayudó a mantener mi atención en la lección (A)

29 El material audiovisual es aburrido (A)

30 Podría relacionar el contenido

$3,54 \quad 1,76$

de esta lección con las cosas que

he visto, hecho o pensado anteriormente $(\mathrm{R})$ 


\begin{tabular}{ccc}
\hline $\begin{array}{c}31 \text { Hay tanto contenido que es } \\
\text { irritante (A) }\end{array}$ & 3,82 & 1,63 \\
\hline $\begin{array}{c}32 \text { Me sentía bien para completar } \\
\text { con éxito esta lección (S) }\end{array}$ & 4,68 & 1,32 \\
\hline $\begin{array}{c}33 \text { El contenido de esta lección } \\
\text { será útil para mí (R) }\end{array}$ & 4,84 & 1,50 \\
\hline $\begin{array}{c}\text { 34 Realmente no pude entender el } \\
\text { material en esta lección (C) }\end{array}$ & 3,18 & 1,55 \\
\hline $\begin{array}{c}\text { 35 La buena organización del } \\
\text { material me ayudó a estar seguro } \\
\text { de que iba a aprender el } \\
\text { contenido (C) }\end{array}$ & 4,88 & 1,27 \\
\hline $\begin{array}{c}\text { 36 Fue un placer trabajar esta } \\
\text { lección que está bien diseñada (S) }\end{array}$ & 4,78 & 1,02 \\
\hline
\end{tabular}

Podemos destacar de la experiencia realizada que la RA les ha llamado la atención (ítems 2, 8 y 28), y que el material les había despertado la curiosidad (ítem 20), les había ayudado a mantener la atención (ítem 11) y habían disfrutado con la experiencia (ítems 14 y 36). Nos hemos encontrado con que para un grupo de alumnos trabajar con estos objetos les ha supuesto cierta dificultad a la hora de desenvolverse en el entorno tecnológico (ítems 3 y 34). De todas formas, los estudiantes sintieron que "los logros alcanzados, le ayudaron a sentirme recompensado por mi esfuerzo" y que "el contenido de ese material fue relevante para sus intereses".

Realizados estos comentarios descriptivos generales, pasaremos a analizar la significación que podría tener el género en la interacción que realizaron; en concreto la hipótesis nula $(\mathrm{H} 0)$ que formularemos se refiere a si el género de los estudiantes no tiene una influencia significativa con un riesgo alfa de equivocarnos del 0,05 o inferior, respecto a la motivación, atención, confianza relevancia y satisfacción despertada por la experiencia. Para su contraste aplicaremos el estadístico " $\mathrm{t}$ " de student para muestras independientes, que para 48 grados de libertad dieron los siguientes valores y nivel de significación: total instrumento: $\mathrm{t}=, 535$ (,595); $\mathrm{A}: \mathrm{t}=1,598(, 117)$; $\mathrm{C}: \mathrm{t}=, 788(, 435) ; \mathrm{R}: \mathrm{t}=, 906(, 370) ; \mathrm{y} \mathrm{S}: \mathrm{t}=, 736$ $(, 413)$.

Como podemos observar los valores $t$ alcanzados no nos permiten rechazar ninguna de las H0 formuladas; en consecuencia podemos decir que el género de los estudiantes no influye en las percepciones alcanzadas en el IMMS y sus diferentes escalas.

Finalmente, y para analizar la influencia de las puntuaciones alcanzadas por los estudiantes en el IMMS, en la interacción que establecían con los diferentes objetos producidos, aplicamos el C.C. de Pearson, alcanzado los siguientes valores: todos los objetos: ,451**; shouder; ,398**; coxofemoral: ,352**; cervical: ,444**; y ankle: ,479**. Señalar que todas las correlaciones obtenidas fueron significativas al nivel del 0,01 y positivas, lo que denota que el tipo de interacción establecida por el alumno con el objeto RA estaba relacionada con el grado de motivación alcanzado en el IMMS.

\section{CONCLUSIONES}

Nuestro estudio permite obtener diferentes conclusiones:

1. El instrumento de diagnóstico, el IMMS de Keller, se presenta como un buen predictor para explicar la motivación, atención, confianza, relevancia y satisfacción que despierta la interacción con los objetos de RA. Y ello es independiente del objeto en RA con que interaccionaban. Por lo que se refiere a la satisfacción nuestro trabajo coincide con los resultados encontrados por diferentes autores (Bongiovani, 2013; Chang, Wu y Hsu, 2013; Han, Jo, Hyun y So, 2015; Kamarainen et al., 2013).

2. Los objetos de aprendizaje en RA se presentan como materiales educativos de utilidad para el aprendizaje de los alumnos de Medicina, aspecto en el que coincidimos con otros autores (Bower et al., 2014; Wu, Wen-Yu, Chang y Liang, 2013; Yeo et al., 2011).

3. Algunos estudiantes han encontrado dificultad a la hora de interaccionar con estos objetos. Ello posiblemente se deba a su falta de experiencia y novedad de la tecnología, hecho que creemos que desaparecerá con un uso más habitual.

4. Su incorporación a la enseñanza es fácil, pues casi todos los alumnos tienen dispositivos móviles y saben descargarse app.

5. El género del estudiante no determina el grado de aceptación que tienen de la RA, lo que coincide con los hallazgos de no relación entre género y tecnologías de otros autores (Bullón et al., 2009; Cabero, Leal, Andrés y Llorente, 2009).

6. Y que el instrumento utilizado posee un nivel de fiabilidad adecuado para su utilización en el diagnóstico de la motivación despertada en los estudiantes al interaccionar con las tecnologías, lo que coincide con los trabajos de otros autores 
(Bolliger, Supanakorn y Boggs, 2010; Chen, 2012; Di Serio, Blanca y Delgado, 2012).

\section{FINANCIACIÓN}

Este artículo forma parte de un proyecto de I + D + I denominado RAFODIUN (EDU2014-57446-P) financiado por el Ministerio de Economía y Competividad.

\section{REFERENCIAS}

Bolliger, D., Supanakorn, S. y Boggs, C. (2010). Impact of podcasting on student motivation in the online learning environment. Computers y Education, 55(2), 714-722.

Bongiovani P. (2013). Realidad aumentada en la escuela: Tecnología, experiencias e ideas. Educ@conTIC. Disponible en http://www.educacontic.es/blog/realidad

Bower, M., Howe, C., McCredie, N., Robinson, A. y Grover, D. (2014). Augmented Reality in education - cases, places and potentials. Educational Media International, 51(1), 1-15.

Bullón, P., Cabero, J., Llorente, M.C., Machuca, M.C., Machuca, G. y Marín, V. (2009). Competencias tecnológicas del profesorado de la Facultad de Odontología de la Universidad de Sevilla. Sevilla: GID.

Cabero, J. y Barroso, J. (2016). The educational possibilities of Augmented Reality. NAER, 5(1), 44-50.

Cabero, J. y García, F. (coord.) (2016). Realidad aumentada. Tecnología para la formación. Madrid: Síntesis.

Cabero, J., Leal, F., Andrés, F. y Llorente, M.C. (2009). La alfabetización digital de los alumnos universitarios mexicanos. Enseñanza y Teaching, 27 (1), 41-59.

Chang, H., Wu, H. y Hsu, Y. (2013). Integrating a mobile augmented reality activity to contextualize student learning of a socioscientific issue. British Journal of Educational Technology, 44 (3): E95-E99.

Chen, Y. (2013). A study of learning effects on e-learning with interactive thematic video. Journal of Educational Computing Research, 47(3), 279-292.

Di Serio, A., Blanca, M. y Delgado, C. (2013) Impact of an augmented reality system on students' motivation for a visual art course. Computers y Education 68, 586-596. doi:10.1016/j.compedu.2012.03.002.

Fombona, J., Pascual, M ${ }^{\mathrm{a}}$ A. y Madeira, M ${ }^{\mathrm{a}}$ F. (2012). Realidad aumentada, una evolución de las aplicaciones de los dispositivos móviles. Píxel-Bit. Revista de medios y Educación, 41, 197-210.

Han, J., Jo, M., Hyun, E. y So, H. (2015). Examining young children's perception toward augmented reality-infused dramatic play. Education Technology Research Development, 63, 455-474.

Johnson, L., Becker, S., Cummins, M., Estrada, V., Freeman, A. y Hall, C. (2016). NMC Horizon Report: 2016 Higher Education Edition. Austin, Texas: The New Media Consortium.

Kamarainen, A., Metcalf, Sh., Grotzer, T., Browne, A., Mazzuca, D., Tutwiler, M., y Dede, Ch. (2013). EcoMOBILE: Integrating augmented reality and probeware with environmental education field trips.
Computers $y \quad$ Education, $\quad 68, \quad 545-556$ doi:10.1016/j.compedu.2013.02.018

Keller, J. M. (2010). Motivational design for learning and performance. New York: Springer Science+Business.

Mateo, J. (2004). La investigación ex-post-facto. In R. Bisquerra (coord.), Metodología de la investigación educativa (pp. 195-230). Madrid: La Muralla.

Mott, J., Bucolo, S., Cuttle, L., Hider, M., Miller, K. y Kimble, R.M. (2008). The efficacy of an augmented virtual reality system to alleviate pain in children undergoing burns dressing changes: A randomised controlled trial. Burns, 34, 803-808.

O'Dwyer, L. y Bernauer, J. (2014). Quantitative research for the qualitative researcher. California: Sage.

Prendes, C. (2015). Realidad aumentada y educación: análisis de experiencias prácticas. Pixel-Bit. Revista de Medios y Educación, 46, 187-203.

Tecnológico de Monterrey (2015). Reporte EduTrends. Radar de Innovación Educativa 2015. Monterrey: Tecnológico de Monterrey.

Wu, H-S, Wen-Yu, S., Chang, H-Y, y Liang, J. (2013). Current status, opportunities and challenges of augmented reality in education. Computers y Education, 62, 41-49. http://dx.doi.org/10.1016/j.compedu.2012.10.024

Yeo, C. T., et al. (2011). The effect of augmented reality training on percutaneous needle placement in spinal facet joint injections. IEEE Transactions on Biomedical Engineering, 58(7), 2031-2037.

\section{ANEXO}

Instrumento de diagnóstico IMMS

$$
\text { Ítem }
$$

1 Cuando vi por primera vez la lección, tuve la impresión de que sería fácil para mí (C)

2 Había algo interesante en los materiales con RA que me llamó la atención (A)

3 Este material es más difícil de entender de lo que me gustaría que fuera $(\mathrm{C})$

4 Después de la información de introducción, me sentí seguro de que yo sabía lo que tenía que aprender de esta lección $(\mathrm{C})$

5 Completar los ejercicios de esta lección me dio una sensación de satisfacción de logro $(\mathrm{S})$

6 Es claro para mí cómo el contenido de este material está relacionado con cosas que ya sé $(\mathrm{R})$

7 La información era tanta que me era difícil recordar los puntos importantes $(\mathrm{C})$

8 La tecnología de la RA me llama la atención (A)

9 No había imágenes, vídeos y textos que me mostraron cómo este material podría ser importante para algunas personas $(\mathrm{R})$

10 Completar esta lección con éxito era importante para mí (R)

11 La calidad del material en RA me ayudó a mantener la atención (A)

$12 \mathrm{El}$ material era tan abstracto que era difícil mantener mi atención en él (A)

13 Mientras trabajaba en esta lección, yo estaba seguro de que podía aprender el contenido $(\mathrm{C})$ 
14 He disfrutado esta lección tanto que me gustaría saber más sobre este tema (S)

15 Las imágenes, vídeos y textos que he descubierto a través de la lección son poco atractivos (A)

$16 \mathrm{El}$ contenido de este material es relevante para mis intereses $(\mathrm{R})$

17 La forma de organizar la información usando esta tecnología me ayudó a mantener la atención (A)

18 Hay explicaciones o ejemplos de cómo la gente usa el conocimiento de esta lección $(\mathrm{R})$

19 Era difícil descubrir la información digital asociada con la imagen real $(\mathrm{C})$

20 La información descubierta a través de la experiencia estimuló mi curiosidad (A)

21 Me gustó mucho el estudio de esta lección (S)

22 La cantidad de repetición de las actividades me aburre (A)

23 El contenido y el material audiovisual en esta lección transmiten la impresión de que su contenido vale la pena conocer $(\mathrm{R})$

$24 \mathrm{He}$ aprendido algunas cosas de la RA que fueron sorprendentes o inesperadas (A)

25 Después de trabajar en esta lección por un tiempo, yo estaba seguro de que iba a ser capaz de pasar una prueba sobre el contenido presentado (C)

26 Esta lección no era relevante para mis necesidades, porque yo ya sabía más del contenido $(\mathrm{R})$

27 Los logros alcanzados, me ayudaron a sentirme recompensado por mi esfuerzo $(\mathrm{S})$

28 La variedad de material audiovisual ayudó a mantener mi atención en la lección (A)

29 El material audiovisual es aburrido (A)

30 Podría relacionar el contenido de esta lección con las cosas que he visto, hecho o pensado anteriormente

31 Hay tanto contenido que es irritante (A)

32 Me sentía bien para completar con éxito esta lección $(\mathrm{S})$

33 El contenido de esta lección será útil para mí $(\mathrm{R})$

34 Realmente no pude entender el material en esta lección $(\mathrm{C})$

35 La buena organización del material me ayudó a estar seguro de que iba a aprender el contenido (C) 36 Fue un placer trabajar esta lección que está bien diseñada $(\mathrm{S})$ 